\title{
Comparative assessment of fracture risk among osteoporosis and osteopenia patients: a cross- sectional study
}

This article was published in the following Dove Press journal: Open Access Rheumatology: Research and Reviews

\author{
Snezana \\ Tomasevic-Todorovic' \\ Atina Vazic ${ }^{2}$ \\ Abukari Issaka ${ }^{3}$ \\ Fahad Hanna ${ }^{4}$ \\ 'Faculty of Medicine, University of \\ Novi Sad, Novi Sad, Serbia; ${ }^{2}$ Higher \\ School, College of Professional \\ Studies in Education of Teachers, \\ Kikinda, Serbia; ${ }^{3}$ Department of \\ Climate and Agriculture, School of \\ Science and Health, Western Sydney \\ University, Sydney, NSW, Australia; \\ ${ }^{4}$ Department of Public Health, College \\ of Health Sciences, Qatar University, \\ Doha, Qatar
}

Correspondence: Fahad Hanna Department of Public Health, College of Health Sciences, Qatar University, PO Box 27/3, Doha, Qatar

Tel +974 4403658 I

Email fhanna@qu.edu.qa
Background: Both osteoporosis and osteopenia remain worldwide public health concerns. They both lead to bone fractures, which can lead to disability and burden on those who are afflicted. Objectives: To assess and compare fracture risk between these two groups of patients.

Patients and methods: Our cross-sectional study included 82 patients ( 46 with osteoporosis and 36 with osteopenia) with an average age of $63 \pm 9.33$ years, who received treatment at the Clinic for Medical Rehabilitation, Clinical Center of Vojvodina in Novi Sad, Serbia. The assessment of the fracture risk was executed by applying the Fracture Assessment Risk (FRAX) index (an algorithm developed by the World Health Organization) based on clinical fracture risks or combination of clinical fracture risks and bone mineral density.

Results: Patients with osteoporosis had significantly higher risk of major fracture compared to patients with osteopenia $(p<0.01)$. Results from FRAX index in osteoporotic patients showed that more than half $(58.70 \%)$ of patients had a low risk of fracture; less than one-third of patients $(30.43 \%)$ had an intermediate risk of major osteoporotic fracture, while almost four out of every $10(39.96 \%)$ had a high risk of hip fracture. The majority of patients with osteopenia (63.89\%) had a low risk of major osteoporotic fracture, while $36.11 \%$ of them had an intermediate risk. The majority of patients with osteopenia $(91.67 \%$ ) had a low risk of hip fracture. Statistically significant differences in relation to specific fracture risks between patients with osteoporosis and osteopenia, in particular, weight $\left(t=-2.250, p=0.027^{*}\right)$ and previous fractures $\left(t=2.985, p=0.004^{* *}\right)$, were established.

Conclusion: Osteoporosis patients had a high risk of major osteoporotic fracture, while there was no association between the intermediate level for major osteoporotic fracture and osteopenia. For patients suffering from an increased fracture risk, especially those who had already been diagnosed with osteoporosis, preventive measures such as designing individual therapeutic programs should be adopted.

Keywords: osteoporosis, osteopenia, fracture risk, fractures, FRAX index, bone fracture, body mass index, bone mineral density

\section{Introduction}

Osteoporosis can be described as a skeletal disorder that is characterized by compromised bone strength, which predisposes individuals to an increased risk of fracture. ${ }^{1}$ Fractures due to osteoporosis may be defined as those that occur as a result of a lowimpact trauma, consequences of which range from chronic pain to institutionalization and death, due to complications. ${ }^{2-7}$ These types of fractures may cause compression of nerve roots and loss of height of few centimeters, which is a visible sign of the disease. With larger deformities, it is possible to have gastrointestinal discomforts and pain after the meal because of increased chest pressure over abdominal organs. Excessive 
muscle and ligament burden on the spine causes chronic, blunt, and persistent pain, especially in the lower back area. Back pain is one of the most significant factors that usurps the quality of life among patients suffering from osteoporotic vertebral fractures. ${ }^{2,3}$

According to the World Health Organization (WHO), osteoporosis occurs when the bone mineral density (BMD) of an individual is $\geq 2.5$ SDs below the young adult mean value (T-score, -2.5 or lower) among postmenopausal women as well as among men aged over 50 years. Kanis et al stated that if the BMD has a T-score of between -1 and -2.5 , the disorder is classified as osteopenia. ${ }^{8}$ Although the most important determinant of fracture risk is low BMD, more than half of all low-trauma fractures occur among people with non-osteoporotic BMD (T-score $>-2.5) .{ }^{9-12}$

The impact on decision about the treatment, beside the determination of BMD by dual-energy X-ray absorptiometry (DXA) method, has been through the assessment of probability of big osteoporotic fracture (spine, hip, forearm, upper arm) by using Fracture Assessment Risk (FRAX) index, which is a clinical instrument defined by Center for Metabolic Bone Disease of WHO (Sheffield, UK). By using FRAX index, it is possible to establish 10-year fracture risk, depending on the age, and life expectancy of clinical fracture risk. ${ }^{13,14}$ The introduction of FRAX index has assisted with the identification of patients of low, intermediate, and high fracture risks. For patients with intermediate fracture risk, some additional prevention measures are advised, such as measuring of femur density and reassessment of the risk. ${ }^{15}$

Women who live in a developed country and aged over 50 years have about a 50\% lifetime risk of sustaining a fracture, while men in that category have a $20 \%$ lifetime risk. ${ }^{16}$ Globally, a bone breaks because of osteoporosis every 3 seconds; and in Europe, India, Japan, and the USA, there are an estimated 125 million people with the disease. ${ }^{17}$ According to a recent global report, the number of people living with osteoporosis is said to increase dramatically in the future, as a result of aging populations and changes in lifestyles. ${ }^{17}$

A recent study by Serbia ${ }^{18}$ found that out of 132 postmenopausal women, about 59\% had normal BMD, whereas $41 \%$ had osteoporosis or osteopenia. The study revealed that about one-third of the patients had a fracture, and the average number of fractures was 1.47 in all the women in the study. There has been extensive research on osteoporosis and osteopenia in Serbia. ${ }^{18-21}$ However, to the best of our knowledge, none of these studies has assessed the fracture risk factors associated with these two conditions, and a standardized FRAX questionnaire was not routinely applied in such assessments.
The purpose of this clinical research was to assess and compare the fracture risk among patients with osteoporosis and those suffering from osteopenia.

\section{Patients and methods}

A cross-sectional analysis was conducted on a group of patients with osteoporosis and others with osteopenia between April and August 2015. Patients who were already enrolled at the Clinic for Medical Rehabilitation (Clinical Centre of Vojvodina) in Novi Sad were invited to participate in this cross-sectional and comparative analysis. Measurements were executed by DXA examination of lumbar spine and proximal femur using the Lunar Prodigy Primo device.

BMD for all patients was measured through DXA examination. $T$-value was used for diagnosing osteoporosis and osteopenia. Osteoporosis is defined as a value for BMD 2.5 SD or more below the young female adult mean (T-score $\leq-2.5$ $\mathrm{SD})$. Severe osteoporosis (established osteoporosis) describes osteoporosis in the presence of one or more fragility fractures. ${ }^{22}$

In this study, we utilized a questionnaire to the participants face-to-face to obtain sociodemographic characteristics, medical history, and fracture history, and 11 questions from FRAX survey to obtain BMD of femoral neck. FRAX is an algorithm developed by the WHO for predicting hip fracture or any other osteoporotic fracture (spine, forearm, shoulder) based on clinical risk factors or a combination of clinical risk factors and BMD. Data obtained from the questionnaire were inserted in a FRAX calculator, which yielded a 10-year-long risk for hip fracture and major osteoporotic fractures (MOFs; hip, vertebral, distal radius, and proximal humerus). By using this clinical instrument, and following the guidelines given by National Osteoporosis Guideline Group (NOGG), patients were divided into three different risk levels (low, intermediate, and high) for occurrence of MOFs and hip fractures as well. ${ }^{22}$ Ten-year risk for hip fracture was found to be higher by $3 \%$, whereas for major fractures, it was higher by $20 \%$, suggesting a treatment for such people.

\section{Statistical analysis}

We used the statistical program International Business Machines, SPSS version 22.0 (IBM Corporation, Armonk, NY, USA). Results were presented using standard statistical measures of central tendency and range of results. For establishing differences in results obtained on scales and subscales from which they were made of, Independent Sample $t$-test was used for testing the difference between the independent samples. Furthermore, only the variables with $p$-values $\leq 0.05$ were considered to be statistically significant. 


\section{Ethical statement}

Ethics approval from the Ethics Committee of the Clinical Center of Vojvodina in Novi Sad, Serbia, was obtained and all participants were enrolled in the study after signing the consent forms provided before entering the study.

\section{Results}

A total of 82 patients, 46 ( 7 men, 39 women) with osteoporosis and 36 (4 men and 32 women) with osteopenia, participated in this cross-sectional study. The average age of patients with osteoporosis was $66.34 \pm 10.23$ years (range 43-88 years), while the average age of patients with osteopenia was $62.44 \pm 7.63$ years (range $48-81$ years). Table 1 presents the characteristics of all participants.

Table I General characteristics of the study participants

\begin{tabular}{lll}
\hline General characteristics & Osteoporosis & Osteopenia \\
\hline Number & 46 & 36 \\
Age (years) & $66.34 \pm 10.23$ & $62.44 \pm 7.63$ \\
DXA, LI-4 & & \\
T score & $-2.61 \pm 1.29^{\mathrm{a}}$ & $-1.03 \pm 1.050^{\mathrm{a}}$ \\
BMD & $1.034 \pm 0.84$ & $1.043 \pm 0.116^{\mathrm{a}}$ \\
DXA femur total & & \\
T score & $-2.38 \pm 0.9 \mathrm{I}^{\mathrm{a}}$ & $-0.90 \pm 0.73^{\mathrm{a}}$ \\
BMD & $0.718 \pm 0.106$ & $0.892 \pm 0.094^{\mathrm{a}}$ \\
\hline
\end{tabular}

Notes: ${ }^{a}$ Statistically significant difference between the groups $(p<0.001)$. Data presented as mean \pm SD.

Abbreviations: BMD, bone mineral density; DXA, dual-energy X-ray absorptiometry.

Table 2 Difference in representation of fracture risks between patients with osteoporosis and patients with osteopenia (Independent Sample $t$-test)

\begin{tabular}{|c|c|c|c|c|c|c|c|}
\hline Fracture risks & Disease type & $\mathbf{N}$ & Mean & SD & $t$ & $d f$ & $p$-value \\
\hline \multirow[t]{2}{*}{ Height } & Osteoporosis & 46 & 161.69 & 8.39 & -0.348 & 80 & 0.729 \\
\hline & Osteopenia & 36 & 162.28 & 6.22 & & & \\
\hline \multirow[t]{2}{*}{ Weight } & Osteoporosis & 46 & 74.33 & 11.58 & -2.250 & 80 & $0.027^{a}$ \\
\hline & Osteopenia & 36 & 68.30 & 12.39 & & & \\
\hline \multirow[t]{2}{*}{ BMI } & Osteoporosis & 46 & 27.77 & 4.57 & -1.034 & 80 & 0.304 \\
\hline & Osteopenia & 36 & 26.43 & 4.34 & & & \\
\hline \multirow[t]{2}{*}{ Menopause } & Osteoporosis & 46 & 0.81 & 0.40 & -1.362 & 80 & 0.177 \\
\hline & Osteopenia & 36 & 0.89 & 0.32 & & & \\
\hline \multirow[t]{2}{*}{ Previous fractures } & Osteoporosis & 46 & 0.65 & 0.48 & 2.985 & 80 & $0.004^{a}$ \\
\hline & Osteopenia & 36 & 0.33 & 0.48 & & & \\
\hline \multirow[t]{2}{*}{ Smoking } & Osteoporosis & 46 & 0.28 & 0.45 & 1.231 & 80 & 0.222 \\
\hline & Osteopenia & 36 & 0.17 & 0.39 & & & \\
\hline \multirow[t]{2}{*}{ Alcohol } & Osteoporosis & 46 & 0.065 & 0.250 & -0.731 & 80 & 0.467 \\
\hline & Osteopenia & 36 & 0.11 & 0.32 & & & \\
\hline \multirow[t]{2}{*}{ Glucocorticoids } & Osteoporosis & 46 & 0.065 & 0.25 & 0.148 & 80 & 0.883 \\
\hline & Osteopenia & 36 & 0.057 & 0.24 & & & \\
\hline \multirow[t]{2}{*}{ Parental history of fracture line } & Osteoporosis & 46 & 0.239 & 0.43 & -0.393 & 80 & 0.695 \\
\hline & Osteopenia & 36 & 0.278 & 0.45 & & & \\
\hline
\end{tabular}

Note: a Difference is statistically significant at 0.05 level. $\mathrm{N}=$ sample size; $t=t$-test scores. Values with significant $\mathrm{p}$-value $(<0.05)$ are bolded. Abbreviations: BMI, body mass index; $d f=$ degrees of freedom.
Statistically significant differences were established in representation of specific fracture risks between the patients with osteoporosis and osteopenia, in particular, weight $\left(t=-2.250, p=0.05^{*}\right)$ and previous fractures $(t=2.985$, $p=0.01^{* *}$; Table 2). Patients suffering from osteopenia had a significantly higher fracture risk compared to patients with osteoporosis, because of their weight, whereas patients suffering from osteoporosis had higher fracture risk in comparison to patients suffering from osteopenia, because of previous fractures (Table 2).

Through FRAX calculator, a 10-year fracture risk of hip fracture was confirmed among the patients with osteoporosis and osteopenia. Based on NOGG guidelines, patients were divided in to three risk levels (low, intermediate, and high) for MOF and hip fracture occurrence (Table 3).

The majority of patients (58.70\%) had a low risk of MOF, less than one-third of patients had an intermediate risk, while $10.87 \%$ had a high risk (Table 3 ).

With regard to hip fracture, the majority of patients with osteoporosis $(56.52 \%)$ had low fracture risk, almost four out of every $10(39.96 \%)$ had high risk, while $6.52 \%$ had intermediate risk (Table 3).

The highest number of patients with osteopenia had low risk level for MOF (23 [63.89\%]), then intermediate (13 [36.11\%]), while the patients with high risk were not accounted for (Table 4).

The majority of patients with osteopenia (91.67\%) had a low risk level for hip fracture; $5.56 \%$ of patients with osteo- 
Table 3 Degree of fracture risk for major osteoporotic fracture and hip fracture for patients with osteoporosis

\begin{tabular}{|c|c|c|c|c|c|c|c|c|}
\hline \multirow[t]{3}{*}{ Fracture type } & \multicolumn{8}{|c|}{ Risk level } \\
\hline & \multicolumn{2}{|c|}{ Low } & \multicolumn{2}{|c|}{ Intermediate } & \multicolumn{2}{|c|}{ High } & \multicolumn{2}{|l|}{ All } \\
\hline & $\mathbf{N}$ & $\%$ & $\mathbf{N}$ & $\%$ & $\mathbf{N}$ & $\%$ & $\mathbf{N}$ & $\%$ \\
\hline Major osteoporosis & 27 & 58.70 & 14 & 30.43 & 5 & 10.87 & 46 & 100 \\
\hline Hip & 26 & 52.56 & 3 & 6.52 & 17 & 39.96 & 46 & 100 \\
\hline
\end{tabular}

Table 4 Degree of fracture risk for major osteoporotic fracture and hip fracture for patients with osteopenia

\begin{tabular}{|c|c|c|c|c|c|c|c|c|}
\hline \multirow[t]{3}{*}{ Fracture type } & \multicolumn{8}{|c|}{ Risk level } \\
\hline & \multicolumn{2}{|c|}{ Low } & \multicolumn{2}{|c|}{ Intermediate } & \multicolumn{2}{|c|}{ High } & \multicolumn{2}{|c|}{ All } \\
\hline & $\overline{\mathbf{N}}$ & $\%$ & $\mathbf{N}$ & $\%$ & $\mathbf{N}$ & $\%$ & $\mathbf{N}$ & $\%$ \\
\hline Major osteoporosis & 23 & 63.89 & 13 & 36.11 & - & - & 36 & 100 \\
\hline Hip & 33 & 91.67 & 1 & 2.78 & 2 & 5.56 & 36 & 100 \\
\hline
\end{tabular}

penia had a high risk level of hip fracture. Only one patient $(2.78 \%)$ had an intermediate risk level of hip fracture (Table 4$)$.

\section{Discussion}

Our study showed that patients suffering from osteopenia had a significantly higher fracture risk compared to those with osteoporosis, with weight being the contributing risk factor. Our results also indicated that patients suffering from osteoporosis and who had history of fractures had higher fracture risk in comparison to those suffering from osteopenia without history of fractures.

It is evident from the extended literature that reduced body weight and previous fractures are risk factors for lower BMD. ${ }^{23,24}$ This is consistent with the findings from our study, which showed that the average value of body mass index (BMI) was $27.77 \pm 4.57 \mathrm{~kg} / \mathrm{m}^{2}$ among the patients with osteoporosis and $26.43 \pm 4.34 \mathrm{~kg} / \mathrm{m}^{2}$ among the patients with osteopenia. Results of previous studies showed that statistically significant differences in representation of particular fracture risks, such as body weight and previous fracture, were determined between patients with osteoporosis and those with osteopenia. ${ }^{24}$ Our study revealed that patients suffering from osteopenia had a higher fracture risk compared to those suffering from osteoporosis, because of the lower body weight, whereas patients suffering from osteoporosis had a higher fracture risk because of previous fractures when compared to patients suffering from osteopenia. These findings are consistent with those from a previous research, which has shown that reduced BMI significantly affects the occurrence of osteoporotic fractures, ${ }^{23}$ and from another study, ${ }^{25}$ which suggested that patients with existing fracture due to osteoporosis have five times the risk of fracture compared to those with no history of fracture.
Our results showed significant difference in average means of fracture risk of the hip between patients with osteoporosis and those with osteopenia. Patients suffering from osteoporosis were found to have a significantly higher risk of hip fracture. This is consistent with reports by Cummings et $\mathrm{al}^{25}$ that BMD of the hip is a stronger predictor of hip fracture than measurements of BMD of other areas of the skeleton. ${ }^{26}$

Data relevant for FRAX index were given for 46 patients with osteoporosis. The low risk of MOF was reported in more number of patients (27 [58.70\%]) than intermediate $(14[30.43 \%])$ and high of MOF $(5[10.87 \%])$. With regard to hip fracture, the low fracture risk is reported in more number of patients with osteoporosis (26 [56.52\%]) , than high (17 [39.96\%]) and intermediate fracture risks (3 [10.00\%]).

In our study, we found that the majority of patients with osteopenia had low risk level for MOF (23 [63.89\%]), with only $13(36.11 \%)$ with intermediate risk, while the patients (33 [91.67\%]) with high risk were not accounted for. In addition, the majority of patients with osteopenia had low risk level for hip fracture, with only one patient (2.78\%) at an intermediate risk level and two (5.56\%) at a high risk. This is contrary to findings from a previous study, ${ }^{27}$ where hip fracture was found to be the most common among the patients with high level of risk (74.2\%), which clearly indicates insufficient recognition of clinical risk factors pertinent to fracture occurrence. Findings from this study would be useful to public health researchers, policy makers, and program managers, in an effort to monitor and design programs and community-based interventional strategies aimed at reducing the risk of osteoporosis and osteopenia in Serbia and surrounding regions and to contribute to the global fight against osteoporotic bone fracture. 
Our study was a cross-sectional study and, therefore, it was impossible to determine the causality. However, these findings provide basis to clinical determination of treatment options and allow some perspectives into the risk of fractures between patients with osteoporosis and those with osteopenia. Moreover, our sample size was relatively small, and while we have had some statistically significant results, a larger sample size could further confirm these findings. Finally, while this study showed that reduced weight can contribute to fracture risk, this is by no means a suggestion that overweight and obesity are protective of osteoporotic fractures. There is a fine line between healthy weight to maintain healthy strong bones and obesity, which can also contribute to fracture risk particularly during falls.

\section{Conclusion}

Reduced body weight and previous fractures have been found to be statistically significant factors in determining fracture risk among patients with osteoporosis and those with osteopenia. Patients suffering from osteoporosis have a higher percentage of major bone fracture, as well as hip fracture. These findings may be useful in the future design of interventional strategies to prevent and reduce fracture risk. Longitudinal studies and larger sample size are needed to further confirm these findings in this population.

\section{Disclosure}

The authors report no conflicts of interest in this work.

\section{References}

1. NIH Consensus Development Panel on Osteoporosis Prevention, Diagnosis, and Therapy. Osteoporosis prevention, diagnosis and therapy. JAMA. 2001;285(6):785-795.

2. Bertram M, Norman R, Kemp L, Vos T. Review of the long-term disability associated with hip fractures. Inj Prev. 2011;17(6):365-370.

3. Naves Díaz M, Díaz López JB, Rodríguez Rebollar A, Gómez Alonso C, Díaz Corte C, Cannata Andía J. [Effect of vertebral fracture on health related quality of life in a Spanish population older than 54 years]. Med Clin (Barc). 2001;116(14):533-535. Spanish.

4. Bliuc D, Nguyen ND, Milch VE, Nguyen TV, Eisman JA, Center JR. Mortality risk associated with low-trauma osteoporotic fracture and subsequent fracture in men and women. JAMA. 2009;301(5): 513-521.

5. Kanis JA, Oden A, Johnell O, De Laet C, Jonsson B. Excess mortality after hospitalisation for vertebral fracture. Osteoporos Int. 2004;15(2):108-112.

6. Johnell O, Kanis J. An estimate of the worldwide prevalence, mortality and disability associated with hip fracture. Osteoporos Int. 2004;15(11):897-902.

7. Johnell O, Kanis JA. An estimate of the worldwide prevalence and disability associated with osteoporotic fractures. Osteoporos Int. 2006;17(12):1726-1733.

8. Kanis JA, Melton LJ 3rd, Christiansen C, Johnston CC, Khaltaev N. The diagnosis of osteoporosis. J Bone Miner Res. 1994;9(8):1137-1141.

9. Schuit S, van der Klift M, Weel AE, et al. Fracture incidence and association with bone mineral density in elderly men and women: the Rotterdam Study. Bone. 2004;34(1):195-202.
10. Sornay-Rendu E, Munoz F, Garnero P, Duboeuf F, Delmas PD. Identification of osteopenic women at high risk of fracture: the OFELY study. J Bone Miner Res. 2005;20(10):1813-1819.

11. Siris ES, Miller PD, Barrett-Connor E, et al. Identification and fracture outcomes of undiagnosed low bone mineral density in postmenopausal women: results from the National Osteoporosis Risk Assessment. JAMA. 2001;286(22):2815-2822.

12. Miller PD, Siris ES, Barrett-Connor E, et al. Prediction of fracture risk in postmenopausal white women with peripheral bone densitometry: evidence from the National Osteoporosis Risk Assessment. J Bone Miner Res. 2002;17(12):2222-2230.

13. Hernlund E, Svedbom A, Ivergård M, et al. Osteoporosis in the European Union: medical management, epidemiology and economic burden. A report prepared in collaboration with the International Osteoporosis Foundation (IOF) and the European Federation of Pharmaceutical Industry Associations (EFPIA). Arch Osteoporos. 2013;8:136.

14. Kanis JA. World Health Organization Scientific Group. Assessment of Osteoporosis at the Primary Health-Care Level Technical Report Sheffield. UK: WHO Collaborating Centre, University of Sheffield; 2008.

15. Compston J, Cooper A, Cooper C, et al; National Osteoporosis Guideline Group (NOGG). Guidelines for the diagnosis and management of osteoporosis in postmenopausal women and men from the age of 50 years in the UK. Maturitas. 2009;62(2):105-108.

16. Sanders KM, Nicholson GC, Ugoni AM, Pasco JA, Seeman E, Kotowicz MA. Health burden of hip and other fractures in Australia beyond 2000. Projections based on the Geelong Osteoporosis Study. Med J Aust. 1999;170(10):467-470.

17. Osteoporosis Fact Sheet [cited February 8, 2017]. Available from: https://www.iofbonehealth.org/sites/default/files/media/PDFs/Fact $\% 20$ Sheets/2014-factsheet-osteoporosis-A4.pdf. Accessed February 8, 2017.

18. Vujasinović-Stupar N, Radojčić L, Tadić I, Pavlov-Dolijanović S. Osteoporosis-related knowledge among Serbian postmenopausal women. Vojnosanit Pregl. 2017;74(5):445-449.

19. Trajkovic K, Perovic M, Tarasjev A, Pilipovic N, Popovic V, Kanazir S. Association of collagen type I $\alpha 1$ gene polymorphism with bone mineral density in osteoporotic women in Serbia. J Womens Health (Larchmt). 2010;19(7):1299-1303.

20. Tasić I, Popović MR, Stojanović S, et al. Osteoporosis-a risk factor for cardiovascular diseases: a follow-up study. Srp Arh Celok Lek. 2015;143(1-2):28-34.

21. Bumbaširević M, Lesić A, Denić-Marković L, Zivković K; ORPHEUM Study Group. Prospective clinical study of once monthly ibandronate in the treatment of osteoporosis and prevention of fractures in postmenopausal women: ORPHEUM Study. Srp Arh Celok Lek. 2011; 139(11-12):790-794.

22. Compston J, Bowring C, Cooper A, et al; National Osteoporosis Guideline Group. Diagnosis and management of osteoporosis in postmenopausal women and older men in the UK: National Osteoporosis Guideline Group (NOGG) update 2013. Maturitas. 2013;75(4):392-396.

23. Ström O, Borgström F, Kanis JA, et al. Osteoporosis: burden, health care provision and opportunities in the EU: a report prepared in collaboration with the International Osteoporosis Foundation (IOF) and the European Federation of Pharmaceutical Industry Associations (EFPIA). Arch Osteoporos. 2011;6(1):59-155.

24. Johnell O, Kanis JA, Odén A, et al. Fracture risk following an osteoporotic fracture. Osteoporosis Int. 2004;15(3):175-179.

25. Cummings SR, Black DM, Nevitt MC, et al. Bone density at various sites for prediction of hip fractures. The Study of Osteoporotic Fractures Research Group. Lancet. 1993;341(8837):72-75.

26. North American Menopause Society. NAMS continuing medical education activity; management of osteoporosis in postmenopausal women: 2010 position statement of the North American Menopause Society. Menopause. 2010;17(1):23-56.

27. Dubljanin-Raspopović E, Markoviü LD, Tuliü G, et al. Prevencija preloma kuka u gerijatrijskoj populaciji-neiskorišćena prilika? [Missed opportunities for prevention of hip fracture in older patients]. Mil Med Pharm J Serbia. 2012;69(5):420-424. Bosnian. 


\section{Publish your work in this journal}

Open Access Rheumatology: Research and Reviews is an international, peerreviewed, open access journal publishing original research, reports, editorials, reviews and commentaries on all aspects of clinical and experimental rheumatology in the clinic and laboratory including the following topics: Pathology, pathophysiology of rheumatological diseases; Investigation, treatment and management of rheumatological diseases; Clinical trials and novel pharmacological approaches for the treatment of rheumatological disorders. The manuscrip management system is completely online and includes a very quick and fair peer-review system, which is all easy to use. Visit http://www.dovepress.com testimonials.php to read real quotes from published authors. 